\title{
Life-course perspective for physical activity and sports participation
}

\author{
Mirja Hirvensalo • Taru Lintunen
}

Received: 4 August 2010 / Accepted: 14 December 2010/Published online: 11 January 2011

(C) European Group for Research into Elderly and Physical Activity (EGREPA) 2011

\begin{abstract}
The purpose of this paper was to discuss physical activity and sports participation in a life-course framework, long-term tracking, determinants, and correlates of physical activity from childhood to old age, and present possible causal links and pathways for the continuity of physical activity. It seems that intensive participation in general in physical activity and sports, as well as participation at school age, are important predictors of adulthood participation. Especially, inactivity rather than activity tends to track from youth to adulthood. Socioeconomic status, place of residence, and personal upward social mobility are related to participation. If physical activity is at a low level in early adulthood, it does not easily become a part of life later on, particularly among blue-collar workers, women, and people with initially poor perceived health. Furthermore, in old age, earlier physical activity seems to be the key determinant along with gender. Repeated social reinforcement in the form of support for autonomy, competence, and relatedness is important especially in transition periods and life events such as secondary schooling, change in employment, and change in family structure. In contrast, retirement presented itself as a good chance of starting new leisure time activities. A life-course approach provides understanding on long-ranging developmental trajectories. According to these results in particular, the polarization of exercise to the active and inactive portions of the population is accumulated over time, and gender and social background features require special attention.
\end{abstract}

\footnotetext{
M. Hirvensalo $(\bowtie) \cdot T$. Lintunen

Department of Sport Sciences, University of Jyväskylä,

P.O. Box 35, 40014 Jyväskylä, Finland

e-mail: mirja.hirvensalo@jyu.fi
}

Keywords Physical activity - Sport participation · Old age . Youth $\cdot$ Adolescence $\cdot$ Adulthood

\section{Introduction}

The life-course perspective has been introduced as a temporal research perspective that can potentially help in understanding physical activity behaviors over the lifespan; in particular, it could be useful for the timing of physical activity interventions [1]. According to life-course theory such as accumulation theory, cross-sectional factors and experiences in different phases of life accumulate longitudinally in later life. The best opportunity to study lifecourse events and exposures in epidemiology is provided by birth cohort studies that can link development and environment to later health outcomes [2]. In general, longitudinal studies create an opportunity to investigate prospectively or retrospectively life-course patterns of physical activity over time and across various life events and transitions. In addition, qualitative studies that involve life reviews and life stories [3, 4] are able to answer different research questions and deepen the quantitative results. Research using the life-course perspective has emphasized the impact of childhood or early life conditions and experiences on adulthood. The transitions (retirement) or events (child birth, death of spouse) at later stages of the life course can also shape the direction of trajectories [5, 6].

In this review, a life-course approach to physical activity and sports participation means studying the tracking of physical activity and the long-term determinants and correlates of physical activity. The determinants and correlates are factors that affect or are related to physical activity such as the demographic and biological, psychological, behavioral, social and cultural, and physical 
environment [7]. Physical activity is discussed as a habit, and other causal links and possible pathways of physical activity are presented. The perspective of longitudinal studies is reported by means of the tracking study review by Telama [8], and by studies from childhood and adolescence to middle adulthood [9-16], in adulthood [17, 18], longtime tracking from young age to old age [19], and in old age [20-25]. Transitions, for example, retirement and life changes, are seen as an opportunity for positive and negative changes in physical activity.

\section{Physical activity and exercise participation}

In the definition of Caspersen et al. [26], physical activity is seen as any voluntary movement produced by the skeletal muscles that result in increased energy expenditure, and exercise is described as a subcategory of physical activity which is planned, structured, and repetitive, with the intent of improving or maintaining one or more patterns of physical fitness or function. Physical activity and exercise can be classified as behaviors, whereas fitness can be classified as performance. When physical activity is understood as a behavior, its longstanding character and cognitive, emotional, and action components are emphasized. The concept of physical activity or sports participation can be seen as voluntary and quite stable physical activity that is measured by type, frequency, intensity, and duration of exercise. It also includes motives and attitudes toward physical activity [27]. The essential element of this definition is consciousness and the attitude of the person himself or herself. For a young person, physical activity participation could be exercising in a sports club for fun or with serious competitive intent, and for an older person, it might also be sports club participation or a walk to the market place or a group-based sport such as water gymnastics for rehabilitation. Often, participation in physical activity is not only based on planned behavior and intention but is performed rather automatically and with less awareness; it could then be defined as a habit. Habit makes a contribution as the automatic component that is strengthened when physically active behavior becomes a routine and is incorporated repeatedly into everyday life [28] such as daily walks, daily home gymnastics, and commuting in a physically active way. Physical activity habits are assumed to develop during childhood through adolescence into adulthood [29]. In addition, the promotion of public health through physical activity interventions and physical education in schools is based on the belief that physical activity is habitual and tracks over time.

Tracking is one of the important concepts of life-course physical activity, while the others are transitions, and determinants and correlates of physical activity in different phases of life. Tracking is usually defined as the tendency of individuals to maintain their rank or position within a group over time [30]. It is expected that physical activity at a young age will have an effect on public health, and a high level of physical activity in youth should predict a high level of physical activity in adulthood. The tracking of inactivity is also an important question from the promotion perspective. The mechanism of tracking and different hypotheses, e.g., the carry-over value hypothesis, ability and readiness hypothesis, and self-selection hypotheses have been presented in the review of tracking studies by Telama [8]. The ability and readiness hypothesis maintains that earlier experiences of physical activities and sports and of the basic skills connected with them make it easy to maintain physical activity or start it again after a possible break, even though the type of activity practiced is different [8]. The concept of carry-over value means that activities in which people participate in adulthood should be learned as early as possible, e.g., in school physical education. The positive experiences and wide range of sports skills acquired in childhood and adolescence could be seen as the preparation for lifelong physical activity. The selfselection hypothesis posits that those individuals who have a hereditary disposition to fitness, early or late maturation in relation to age-mates, or motor performance participate more often in physical activity both at a young age and in adulthood than those who do not have the same disposition [8]. In addition to physical activity, these three models and explanations fit into physical activity motivation.

Self-determination theory (SDT) [31-34], a meta-theory for framing motivational studies, defines that intrinsic and varied extrinsic sources of motivation have an effect on cognitive and social development and on individual differences. Self-determination theory has become a salient motivational theory in recent years and has received a great deal of research attention. The theory propositions focus on how social and cultural factors facilitate or undermine people's sense of volition and initiative, in addition to their well-being and the quality of their performance. It is argued that conditions supporting the individual's experience of autonomy, competence, and relatedness foster the most volitional and high quality forms of motivation and engagement for activities, including enhanced performance and persistence in physical activity. Autonomy refers to the belief that one has some level of control over whether to participate in physical activity. Competence refers to the belief that a person possesses sufficient ability to cope in a specific situation, and relatedness is how connected a person feels to those around, such as parents, peers, and colleagues. The stability of perceived competence has been studied to some extent. However, hardly any tracking research exists on perceived autonomy and relatedness. 
Perceived physical competence is relatively stable over time [30]. However, we do not know how modifiable perceived competence is during the lifespan. When it has been formed, it may crystallize into a stable characteristic or it may remain stable because the environment remains unchanged for many people.

\section{Physical activity participation in longitudinal studies}

Longitudinal studies provide an opportunity to study prospectively or retrospectively physical activity over time and whether physical activity already in youth leads to a certain pathway with consequences for later activity and well-being. These studies are relatively scarce because they require a large financial effort and the long-term commitment of subjects, and encounter certain problems such as changing measurement techniques, a changing concept of physical activity, and confounding effects that occur in repeated measurements [35]. The concept of physical activity may have varied; those who, nowadays, know that when they walk somewhere (shopping, work), they are taking exercise might not recognize this earlier in life (e.g., 30 years previously). Socioeconomic status may be a confounding effect that occurs in repeated measurements in different ways; those with higher status continue participating more often in later phases of life.

Most commonly, physical activity is studied across two or three time points, for example, using Spearman's rank order correlations in tracking studies; across childhood into adolescence, from adolescence into young adulthood, and during adulthood. Other methods for considering activity stability or change in activity include using baseline characteristics to predict physical activity and fitness several years later and relating current activity with retrospective recall of earlier activity levels.

From childhood to adolescence and adulthood

Early physical activity in childhood and adolescence predicts a physically active lifestyle in adulthood $[9,12$, 13, 36, 37]. However, the tracking of physical activity during transitions from childhood to adulthood and adolescence to adulthood has been shown to be quite low, while the tracking of physical activity during adult life is somewhat higher $[8,30]$. From early ages $(7-11$ years) to middle adulthood, Spearman's rank order correlations have been found to be from 0.03 to .035 and from adolescence to adulthood from 0.15 to 0.44 for men and for 0.09 to 0.34 women [8]. The low tracking correlation indicates that many other factors influence physical activity in adulthood. Low tracking correlations may also be due to measurement errors. Education, occupation, living environment, marital status, having children, and health attitudes have been found to be important factors for later activity [9, 12, 15].

As early as 1992, Kuh and Cooper [9] examined the influence of childhood activity on adult activity patterns in work and leisure in a national sample in England, Scotland, and Wales of over 3,300 men and women aged 36 years from a birth cohort of the year 1946. Those who were most active in sport in adulthood had been above average at sports in school, more outgoing socially in adolescence, had fewer health problems in childhood, were better educated, and had more mothers with a secondary education than those who were less active. Two decades later, Mäkinen et al. [10] studied a representative sample of Finns aged $\geq 30$ years in 2000-2001 and found that childhood socioeconomic conditions had an effect in leisure-time physical activity. The direct effect of childhood socioeconomic conditions on educational differences in inactivity was stronger than its indirect effects through adulthood socioeconomic conditions and other health behaviors. Tammelin et al. [12] studied a Finnish cohort of 8,000 men and women at ages 14 and 31 in follow-up surveys of the Northern Finland 1966 birth cohort. Their results suggest an association between father's occupation and type of sport. Participants in downhill skiing, dancing, orienteering, and riding came from families of the highest social class, and participants in strength sports, walking, cycling, and soccer came more commonly from families of low social class. They also found associations between participation in some sports with high grades in school sports and membership of a sports club that carried over into adult years. In addition, Cleland et al. [15] found that a persistently high socioeconomic position and upward social mobility were associated with increases in self-reported physical activity and objectively measured fitness from childhood to adulthood among over 2,000 Australian adults aged 26-36 who had first been examined between the ages of 7 and 15. Upward social mobility, defined as reaching a higher level of educational attainment than one's parents, was associated with a greater likelihood of high physical activity in adulthood and a greater likelihood of a high fitness level. The results of secular trends in the Finnish Adolescent Health and Lifestyle Survey from 1977 to 2005 [16] showed that participation in youth sport organized by sport clubs was strongly associated with parental socioeconomic status over a period of 28 years in both sexes. Social inequality was smaller in sport organized by schools and in young people's spontaneous physical activities. Participation in physical activity is unevenly distributed across population groups. Various writers have discussed [12, 15, 16] that associations between childhood socioeconomic position, social mobility, and physical activity and fitness may run through the mechanisms, such as improved socioeconomic circumstances leading to greater social or 
economic and psychological support for physical activity for example through more flexible work hours and higher income; a low social class may weaken parents' ability to transport children to organized sports, as well as to afford the fees and equipment required for the young person to participate.

Biological and psychological determinants and correlates are also crucial to the stability of physical activity. Allender et al. [38] found in their review of qualitative studies of motives and barriers that body shape and weight management are the important reasons behind the participation of girls in adolescence. Those who participated from youth to adulthood recalled the importance of positive influences at school in becoming and staying physically active (good teachers, friends). Instead, competitive classes, a lack of teacher support, negative experiences at school, and peer pressure and identity conflict were the major barriers to physical activity. The findings of Lunn [39] suggest that there is a gender gap in team sports but not in individual sports; boys are many times more active in team sports. Participation in sports and exercise activities moves closer to gender equality once individuals enter adulthood, where presumably they have greater choice and autonomy with respect to leisure-time activities.

It is important to investigate also the stability of various physical activities from childhood and adolescence to adulthood, and analyze how well adult physical activity can be predicted by physical activities measured in childhood and adolescence to obtain information for prevention and physical education about factors that may be relevant to later activity. In the study of cardiovascular risk in Young Finns [13], a random sample of 3,500 children, surveyed in 1980 and 2001, is analyzed. The aim was to reveal the influence of the type of sport practiced in youth on adult physical activity. The results indicated that a high level of physical activity at ages 9-18, especially when it was continuous, significantly predicted a high level of adult physical activity and that the level of activity in adulthood did not depend on the type of physical activity at a young age. It seems that intensive participation in general in physical activity and sports, and continuous participation at school age in particular, were more important than participation in specific sports. In addition, when Tammelin et al. [12] evaluated the association between participation in different types of adolescent sports and physical activity in adulthood, they found that very different types of participation in adolescence were beneficial with respect to the enhancement of adult physical activity. Adolescent participation in intensive endurance sports, such as cross-country skiing, running, orienteering, as well as certain sports that require and encourage diversified sports skills, such as ice hockey, soccer, volleyball, track and field, gymnastics, and riding and combat sports, was associated with a high or very high level of adult activity. Matton et al. [14] found that fitness characteristics demonstrated higher levels of stability from adolescence to middle adulthood than physical activity, and inactivity rather than activity tended to continue from youth to adulthood when they studied the stability of the physical fitness and physical activity of 138 women from adolescence (17 years of age) into adulthood (40 years of age) in Flemish women in the Leuven Longitudinal Study. Similar results were reported in the Amsterdam Growth and Health Study. The tracking of daily physical activity and physical fitness along with cardiovascular disease risk factors was investigated by means of six repeated measurements of 5,100 subjects over a period from 13 to 27 years of age [11]. The total time spent on all habitual physical activities in relation to school, work, sports, and on other leisure time activities was measured and calculated with the intensity to energy expiatory MET scores. Low to moderate tracking was observed for daily physical activity and $\mathrm{VO}_{2}$ max, whereas good tracking was observed for neuromotor fitness. In contrast, daily physical activity seemed to predict activity clearly from early years to adulthood - an odds ratio of 3.6 was found-indicating that those in the lowest quartile for physical activity at the age of 13 were 3.6 times more likely to remain in the lowest quartile along the measurement period of 15 years than those in the upper three quartiles at the age of 13 .

\section{In adulthood}

The tracking coefficients during adulthood have been moderate, from 0.35 to 0.65 , and seem to be smaller when the follow-up period has been longer [8]. The stability in a Finnish study over 5 years in 18-64-year-old male and for female subjects was 0.46 and 0.34 , and stability over 10 years was 0.25 and 0.29 , respectively [18]. The study examined both the tracking of physical activity and the effect of earlier physical activity and other lifestyle and socio-demographic determinants of sport, exercise, recreation, and housework physical activity. The level of physical activity at baseline was a good predictor of activity during the follow-up stages. Changes along the follow-up reflect a polarization of the distributions of physical activity within the sample. Low activity, old age, smoking, a blue-collar occupation, female gender, a high body mass index, and poor perceived health were significant predictors of inactivity in the 5-year follow-up in 1978, whereas old age, smoking, and low activity were predictors in the 10-year follow-up in 1983. In the model for the 28-year follow-up, in 2000, the dominant factors were age, along with female gender, a blue-collar occupation, smoking, poor perceived health, and low initial activity. Age and an initially low level of activity were the strongest predictors of inactivity. A similar gender difference was found in the 
study of Fortier et al. [17] with male subjects showing greater stability and higher physical activity levels than with female subjects. The study compared the tracking of physical activity levels between male and female subjects during middle adulthood. The Canadian sample comprised 1,900 subjects, aged 11-69 years, in the 1981 Canada Fitness Survey and its 7-year follow-up, the Campbell's Survey. The measures of physical activity were estimated activity energy expenditure and time spent on activity. Significant tracking correlations for physical activity levels were limited to adulthood, whereas significant tracking of musculoskeletal fitness was observed at all ages. The results suggest that the level of physical activity has greater plasticity than musculoskeletal fitness and is thus subject to greater change.

Individual determinants such as personality have been recognized as an important correlate of physical activity [40], e.g., in the Terman Life-Cycle Study, a lifespan longitudinal cohort study, Friedman et al. [19] found that childhood energy and activity ratings correlated with adult activity. They examined the activity levels of 723 men and 554 women. The sample originally consisted of middle class boys and girls. Childhood activity and interests were assessed in 1922 by parents, who evaluated their children's "hobbies or enterprises." Additionally, participants indicated how much they enjoyed playing games that required lots of exercise. These ratings were averaged to indicate childhood interest in being physically active. Adult physical activity was assessed in 1936, 1940, 1950, 1960, and 1972. In 1977, when the participants were, on average, 67 years old, individuals were asked about their level of participation in various activities. The results showed activity levels were somewhat stable from childhood through middle and late adulthood. Active, energetic children tended to become active, energetic adults, and in turn tended to remain active.

These studies, the Kirjonen et al. study [18] and the Friedman et al. [19] study spanning many decades, and also the Frontier study [17] sample including subjects aged 11-69 years suggest that there are very long-term consistencies in levels of physical activity and that fitness and inactivity tends to track better than activity. On the other hand, the level of physical activity has greater plasticity than fitness and is thus subject to greater change [17]. If interest in voluntary physical activity is lacking during early adulthood, it does not easily become a part of life later on, particularly among blue-collar workers, women, and people with initially poor perceived health.

\section{In old age}

There are only a few tracking studies that extend into old age [17-19], and it is difficult to see any systematic age differences in the tracking coefficients reported in the different phases of life, the coefficients being quite low from childhood to adulthood and at most moderate in adulthood [8]. When the subjects have already reached older age, the activity profiles have been shown to be quite stable. The Nottingham Longitudinal Study found that both the activity profiles and the time spent on various activities were quite stable over an 8-year follow-up in subjects aged 65-74-years at the baseline. The 8-year stability correlations in outdoor activities and men's walking and leisure activities were moderate $(0.45-0.58)$ [21]. Within the cohorts of older people, traditional gender roles continue to exert an influence with women showing higher levels of activity participation indoors and men showing higher levels of activity participation outdoors. In levels of walking/shopping activity, however, there was evidence of gender differences narrowing over time [22]. The major sources of change might plausibly include declining health with reduced physical ability, widowhood, and adaptive moves into specialized, but less spacious accommodation.

The Evergreen study in Finland [23] found that men's physical activity level decreased less than women's level over an 8-year follow-up with non-institutionalized seniors aged 65-84 years at baseline in 1988. The study examined changes in subjects' involvement in various types of physical exercise, and the motives for and obstacles to participation. Men took part in a wider range of leisure time physical activities and sports than women, and their participation in supervised exercise classes and doing calisthenics exercises at home increased over the followup, while in the case of women, the general trend was that physical exercise declined during the follow-up. In the same Evergreen study project, the continuity of lifespan physical activity was studied [24] by examining the predictors of maintaining a high level of physical activity over 8 years of follow-up. For men and women, selfreported competitive sport participation from as early as 10-19 years of age was a significant predictor of maintaining physical activity in old age regardless of chronic conditions. Women's participation in recreational sports at the age of 40-64 years also predicted activity. Bonsdorf et al. [25] studied the same participants in their 16-year follow-up in 2004. The association of self-reported physical activity from midlife to old age and all-cause hospital and long-term care in the last year of life was studied. Men who reported consistent physical activity from midlife onward needed fewer days of hospital care in their last year of life than those who reported less physical activity. For women who died before 90 years of age, the same was true for long-term care.

In the longitudinal study in Gothenburg, Sweden [20] of 293 women and 233 men, the relation between the level of physical activity in earlier life and both physical activity and performance at age 76 was analyzed. The lifespan was 
divided into five age periods from the age of 10 and described as competitive sport, recreational sport, occupational physical load, household work, and means of transportation. The Swedish results revealed that the earliest periods could not explain activity patterns or performance late in life when all fields of activity were combined into a total measure of physical activity. After the age of 35 years in men and 50 years in women, however, the associations grew stronger, and the activity level of the last life period (66-76) was strongly correlated with physical activity in old age. When, on the other hand, each field of activity was treated alone, above all recreational sport turned out to be positively related to walking speed and physical activity at age 76 in both women and men for most life periods.

Earlier physical activity seems to be the most important determinant, along with gender, in old age. Probably, the cumulative effects of different determinants still affect physical activity in old age. This may be due, at least in part, to gender-role expectations that have been assimilated over the years and that still apply in old age, namely, that it is more appropriate for men to be active than it is for the women. O'Brien Cousins and Vertinsky [41] conducted life-course interviews with women born in or before 1890 , and Kluge et al. [4] explored the nature and meaning of being physically active in women aged 65 and older. Both studies found that the late life exercise patterns of elderly women appear rooted in their pasts. These physically active women hung on to a concept of themselves as physically active. However, findings suggest that the continuity of a physically active lifestyle was affected by gender socialization, ageist attitudes, and physical challenges. In addition, they found that social empowerment during adulthood and a commitment to exercise through later life were important to remaining physically active. Older women judge their efficacy for exercise based on their understanding of perceived health, chronological age, and previous skills [42]. The findings support the self-determination theory, which argues that experiences about physical competence might have roots in early mastery experiences. In most cases, positive social support from parents, peers, and teachers was a feature of the participants' early experiences of physical activity.

The attitudes of older people toward physical activity may sometimes be undermined by prevailing attitudes that older people are passive members of society who need to rest. Long working hours and other responsibilities may have prevented people from participating in physical activity in earlier life, and thus, exercise skills have not developed. In addition, physical activity behaviour is susceptible to changes in environmental factors, such as latent age discrimination in exercise clubs, the accessibility of exercise facilities, leadership, and role models. For example, in a systematic review of qualitative research into barriers and motivations to physical activity [43], older adults identified cost and time barriers as the main problems. The lack of realistic role models in the community was a deterrent. Exercise prescriptions were perceived as targeted at young people and not relevant to older groups. Some older adults were unsure about the "right amount" of physical activity for someone of their age. The health benefits of physical activity were emphasized in terms of reducing the effects of aging and being fit and able to play with the grandchildren. The studies reviewed also highlighted the importance of social networks in maintaining participation.

\section{The role of transitions and life changes}

Lifespan is characterized by various important, temporally arranged transitions. These include the transition from early childhood to formal schooling, the transition from childhood to puberty, the transition from school to the work, marriage, children with associated responsibilities, and retirement. In addition to these transitions are factors or life events that may influence the transitions or create new ones, for example, the occurrence of a disease, job changes, ecological and social and political events (changes in political power, war, etc.). Earlier events in the life span may condition later events and in turn influence patterns of stability (tracking) or instability (change, low tracking). Earlier events may thus predict the present levels of activity, but they do not predict the future. Changes in patterns of physical activity related to specific events in the lifespan help us to better understand the stability or instability of habitual physical activity in individuals and groups [30].

It is important to study transitions and life changes because individuals or groups may be more receptive to health-promoting interventions around the times of these transitions [44]. However, it is currently somewhat unclear which transitions are most important and what factors are associated with changes in physical activity at these times. Physical activity behavior changes over the life course, and individuals add and delete behaviors in their life, but sometimes, changes may be gradual or changes in physical activity behavior may occur during periods of life transition when individuals' roles, relationships, and ecological contexts are altered. The transition from one school to the next, going to college or university, marriage, becoming a parent, and retirement have been found to be periods for change in physical activity behavior $[45,46]$. In a review by Allender et al. [47], which consists of 19 publications, five life change categories were found: change in employment status, change in residence, change in physical status, change in relationships, and change in family structure. The 
review suggests that life change events affect participation in physical activity, generally decreasing participation after a change in employment or a change in residence status or having children, but having no effect during pregnancy, or even producing some increase in participation. After serious diseases, the results have varied; in two studies of women with cancer, Pinto et al. [48] found no change in exercise participation, but Satia et al. [49] reported an increase in physical activity participation over a 2-year period of follow-up. Brown et al. [50] studied young (22-27 years), middle-aged (51-56 years), and older (73-78 years) Australian women on two occasions, 3 years apart. Decreasing physical activity was associated with marriage and childbirth in young women and with declining health in older women. Increasing physical activity was associated with retirement and the death of a spouse in the middle-aged women. Stressful events such as divorce, harassment at work, and violence were also associated with changing physical activity.

Lunn et al. [39] presented some interesting recall data from a representative sample of 3,080 adults with a median age of 41 in Ireland. The study identified key transitions in the sports and exercise life course. Among the various significant associations, the importance of the period around the end of secondary schooling and the change in the relationship between the sexes was emphasized. The likelihood of making the transition from secondary schooling and hence continuing to participate in later adulthood is strongly linked to background characteristics, especially socioeconomic status. Income and educational attainment seemed to be a strong determinant of participation, especially of taking up individual activities. The findings revealed that participation in sports and exercise is higher in more recent cohorts.

Retirement allows people ample opportunity to be physically active in their leisure time. There are also social factors and particular times of life among adults and older adults in retirement, which may have an adverse effect on participation in physical activity, such as becoming disabled and the death of a spouse. Thus, also the results in different studies have varied. Slingerland et al. [6] examined the effect of retirement on changes in physical activity in the GLOBEStudy, in the Dutch 13-year prospective follow-up into retirement of employees aged 40-65 years at baseline after which they were still employed or had retired. Physical activity included work-related transportation, sports participation, and other leisure-time physical activity. They found that physical activity associated with workrelated transportation greatly decreased and that the reduction was not compensated by increased sports participation or other leisure-time physical activity. Touvier et al. [50] investigated the relationships between retirement and 3 -year changes in leisure-time physical activity patterns and sedentary behavior (watching television) in middle-aged 45-64-year-old French adults. Mean leisure-time physical activity increased by about $2 \mathrm{~h} /$ week in men and women who had retired, whereas no change was observed in employed persons. The positive change in leisure-time physical activity following retirement was mainly related to an increase in activities of moderate intensity, such as walking. Retirement did not modify the ranking of the most frequently performed leisure time physical activities, but the number of participants and the duration increased through retirement. Retirement was also associated with time spent watching TV. The study by Chung et al. [51] found that physical activity decreased with retirement from a physically demanding job but increased with retirement from a sedentary job in the Health and Retirement Study (1996-2002) conducted in the USA.

It is probable that many transitions and life events are important and individually, socially, and economically determined, and thus, there are also multiple possibilities why people become physically active. It seems that already from very a young age, physical activity and sports participation are a key factor in building a future physically active lifestyle and thus a long-lasting habit. In some studies, retirement appears to be associated with a relative reduction in physical activity [6], although leisure time physical activity may increase [6, 51, 52], while the objective opportunities for being more physically active are better after retirement. Being physically active in older age has great health benefits, and it is important that physical activity promotion is targeted toward people who are preparing for retirement and who have recently retired.

\section{Promotion of physical activity over the life course}

The factors that influence physical activity during the life course are many, and most studies of tracking do not include such correlates or covariates. However, programs and policies will benefit from more information on the reasons why and when people start a physically active way of life or discovering whether critical times for stopping participation exist. Why do some people maintain their physical activity over long time periods while others remain inactive? What determinants are related to changing to a more active or more inactive lifestyle? Li et al. [1] found in their review article that relatively little is known about decline in physically active lifestyle, including whether it occurs in all domains of physical activity. Of special interest from a population health and prevention perspective is identifying the characteristics of those who maintain their level of capability and function at a higher level than would be expected from their lifetime exposure, or are able to recover after adverse health events [2]. The role of physical 
activity may be very important. There is presumably a wide continuum of physical activity levels among people with and without health problems, and it is known that despite the overall greater risk, people with even severe health problems may be able to prevent further disability and mortality by means of physical exercise [53].

Implications for how physical activity policy is applied over the life course suggests targeting lower socioeconomic groups in early adulthood, offering special support from teachers and a broader range of activities to young women. A wide range of extracurricular physical activities should be provided by schools and more opportunities made available for self-organized activities close to residential areas to decrease social inequality. In addition, a child needs physical competence, parent support, direct helps from parents, and support from significant others, e.g., peers [7].

In adulthood, when physical activity is seen as sociocultural by nature, the need for repeated social reinforcement especially in transition periods or life change periods, such as a change in employment status, change of residence, and change in family structure, is emphasized [47]. At the individual level, being obese, a smoker, and less well-educated may increase the probability of remaining sedentary. Starting and keeping up physical activities during one's adult years require determination. The challenge seems to be simultaneously personal and political. One of the challenges facing politicians and professionals is to understand difficulties at the individual level and the structural aspects behind people's behavior. Information on the negative side of tracking is important in the planning of intervention. It may be a kind of chain reaction-older habits (especially inactivity) seem to remain unchanged in different stages of life. However, earlier experiences could be transformed again by later positive experiences, e.g., interventions that increase levels of physical activity in the short term could be a start to increasing long-term physical activity and also health and longevity. Intervention conditions supporting the individual's experience of autonomy, competence, and relatedness may generate fruitful consequences [33]. There is also a need for ecological and cultural support such as the World Health Organization's project Healthy Cities [54], which identified a wide range of aspects and determinants that exert an influence at the community level. These include neighborhoods and safe routes to work that encourage walking and cycling, providing opportunities for physical activity at the workplace (such as fitness programs, showers, and changing rooms) and creating opportunities for work colleagues to be active together during breaks and after work hours.

All in all, the ongoing improvements in the educational level, health status, and functional capacity of the elderly population probably enable a larger proportion of older people than previously to exercise. Furthermore, seeing old age as an active phase of life is becoming the predominant view in present-day society. Culture and policy in communities and society as a whole are key determinants of physical activity. The European Network for Action on Aging and Physical Activity proposed that national policy approaches should be sought to increase physical activity for older adults [55]. Effective policy approaches are enhanced access to physical activity places (e.g., groups, transportation to venues for physical activity), urban planning approaches, and infrastructure changes. In addition, life transitions such as retirement may be a new opportunity to start a more active lifestyle, especially in terms of leisure-time physical activity. For older people, regular physical activity is pictured as an important lifestyle behavior, which increases active life expectancy through its influence on chronic disease risk factors, and is associated with better mental and cognitive health $[56,57]$ and social integration [58]. A recent American College of Sport Medicine Position Stand provides a summary of the most important issues connected with exercise and physical activity in older adults [59]. Several evidence-based conclusions were drawn from exercise and physical activity programs on health and functional capacity in previously sedentary individuals. One of these was the conclusion that physical activity self-efficacy is an important predictor of sustained behavioral change in sedentary populations [60]. The elderly population requires special attention, and supporting the individual's experience of autonomy, competence, and relatedness is essential to form motivation and persistence in physical activity $[31,32,34]$. The satisfaction of these basic needs through physical activity provides older people with enjoyment and intrinsic motivation. Extending and applying recent advances grounded in selfdetermination theory over the life course would potentially help in understanding older people's physical activity behaviors [61].

\section{Conclusion}

An individual's cultural and socioeconomic background may produce a cumulative increase or decrease in activity in different phases of life that accentuates differentiations in physically active lifestyle. It is essential to accept that there is clear polarization by gender and social background in lifelong physical activity behavior. For physical and health education and interventions, it is important to be familiar with people's earlier activity levels and past attitudes in order that those who are not so active can be helped appropriately to adopt new activities. Positive patterns should be created as early as possible by means of new skills and good experiences and sustained supporting of autonomy, competence, and relatedness in those who have 
the most to gain from adopting them. There is a clear need for more long-term intervention studies and repeated follow-up assessments to track the process of adherence and relapse. Future research could focus more on the longterm pathways for a lower or higher level of physical activity in different social circumstances and on interventions for these groups, the role played by physical activity in various life transitions, and the processes of possible accumulation effects.

\section{References}

1. Li K-K, Cardinal BJ, Settersten RA Jr (2009) A life-course perspective on physical activity promotion: applications and implications. Quest 61:336-352

2. Kuh D (2007) A life course approach to healthy aging, frailty, and capability. J Gerontol A Biol Sci Med Sci 62:717-721

3. Clausen JA (1998) Life reviews and life stories. In: Giele JZ, Elder GH Jr (eds) Methods of life course research: qualitative and quantitative approaches. Thousand Oaks, Sage, pp 189-212

4. Kluge MA (2002) Understanding the essence of a physically active lifestyle: a phenomenological study of women 65 and older. J Aging Phys Act 10:4-27

5. Devine CM, Bove CF, Olson CM (2000) Continuity and change in women's weight orientations and lifestyle practices through pregnancy and the postpartum period: the influence of life course trajectories and transitional events. Soc Sci Med 50:567-582

6. Slingerland AB, van Lenthe FJ, Jukema JW et al (2007) Aging, retirement, and changes in physical activity: prospective cohort findings from the globe study. Am J Epidemiol 165:1356-1363

7. Sallis J, Prochaska JJ, Taylor W (2000) A review of correlates of physical activity of children and adolescents. Med Sci Sports Exerc 32:963-975

8. Telama R (2009) Tracking of physical activity from childhood to adulthood: a review. Obes Facts 2:187-195

9. Kuh DJ, Cooper C (1992) Physical activity at 36 years: patterns and childhood predictors in a longitudinal study. J Epidemiol Community Health 46:114-119

10. Mäkinen T, Kestilä L, Borodulin K, Martelin T, Rahkonen O, Prättälä R (2010) Effects of childhood socio-economic conditions on educational differences in leisure-time physical activity. Eur J Public Health 20:346-353

11. Twisk JWR, Kemper HCG, Van Mechelen W (2000) Tracking of activity and fitness and the relationship with cardiovascular disease risk factors. Med Sci Sports Exerc 32:1455-1461

12. Tammelin T, Näyha S, Hills AP, Jarvelin M-R (2003) Adolescent participation in sports and adult physical activity. Am J Prev Med 24:22-28

13. Telama R, Yang X, Viikari J, Välimäki I, Wanne $O$, Raitakari $O$ (2005) Physical activity from childhood to adulthood: a 21-year tracking study. Am J Prev Med 28:267-27311

14. Matton LM, Thomis K, Wijndaele N et al (2006) Tracking of physical fitness and physical activity from youth to adulthood in females. Med Sci Sports Exerc 38:1114-1120

15. Cleland VJ, Ball K, Magnussen C et al (2009) Socioeconomic position and the tracking of physical activity and cardiorespiratory fitness from childhood to adulthood. Am J Epidemiol 170:10691077

16. Telama R, Laakso L, Nupponen H, Rimpelä A, Pere L (2009) Secular trends in youth physical activity and parents' socioeconomic status from 1977 to 2005. Pediatr Exerc Sci 21:462474
17. Fortier MD, Katzmarzyk PT, Malina RM, Bouchard C (2001) Seven-year stability and musculoskeletal fitness in the Canadian population. Med Sci Sports Exerc 33:1905-1911

18. Kirjonen J, Telama R, Luukkonen R, Kääriä K, Kaila-Kangas L, Leino-Arjas P (2006) Stability and prediction of physical activity in 5-, 10-, and 28-year follow-up studies among industrial employees. Scand J Med Sci Sports 16:201-208

19. Friedman HS, Martin LR, Tucker JS, Criqui MH, Kern ML, Reynolds CA (2008) Stability of physical activity across the lifespan. J Health Psychol 13:1092

20. Frändin K, Mellström D, Sundh V, Grimby G (1995) A life span perspective on patterns of physical activity and functional performance at the age of 76. Gerontology 41:109-120

21. Amstrong GK, Morgan K (1998) Stability and change in levels of habitual physical activity in later life. Age Ageing 53:17-23

22. Bennett KM (1998) Gender and longitudinal changes in physical activities in later life. Age Ageing S3:24-28

23. Hirvensalo M, Lampinen P, Rantanen T (1998) Physical exercise in old age: an 8 year follow-up study on involvement, motives and obstacles among persons age 65-84. J Aging Phys Act 6:157-168

24. Hirvensalo M, Lintunen T, Rantanen T (2000) The continuity of physical activity - a retrospective and prospective study among older people. Scand J Med Sci Sports 10:37-41

25. von Bonsdorff MB, Rantanen T, Leinonen R, Kujala UM, Törmäkangas T, Mänty M, Heikkinen E (2009) Physical activity history and end-of-life hospital and long-term care. J Gerontol A Biol Sci Med Sci 64:778-784

26. Caspersen CJ, Powell KE, Christenson GM (1985) Physical activity, exercise, and physical fitness: definitions and distinctions for health-related research. Public Health Rep 100:126-131

27. Telama R, Yang X, Laakso L, Viikari J (1997) Physical activity in childhood and adolescence as predictor on physical activity in young adulthood. Am J Prev Med 13:317-323

28. Verplanken B, Melkevik O (2008) Predicting habit: the case of physical exercise. Psycholol Sport Exerc 9:15-26

29. Malina RM (1996) Tracking of physical activity and physical fitness across the lifespan. Review. Res Q Exerc Sport 67:S48S57

30. Malina RM (2001) Tracking physical activity across the life span. PCPFS Res Dig 3:1-8

31. Deci EL, Ryan RM (1985) Intrinsic motivation and selfdetermination in human behavior. Plenum, New York

32. Deci EL, Ryan RM (2000) The "what" and "why" of goal pursuits: human needs and the self-determination of behavior. Psychol Inq 11:227-268

33. Hagger MS, Chatzisarantis NL (2007) Intrinsic motivation and self-determination in exercise and sport. Human Kinetics, Champaigne

34. Deci EL, Ryan RM (2000) Self-determination theory and the facilitation of intrinsic motivation, social development, and wellbeing. Am Psychol 55:68-78

35. Wadsworth MEJ, Butterworth SL, Hardy RJ, Kuh DJ, Richards M, Langenberg C, Hilder WS, Connor M (2003) The life course prospective design: an example of benefits and problems associated with study longevity. Soc Sci Med 57:21932205

36. Engström LM (1991) Exercise adherence in sport for all from youth to adulthood. In: Oja P, Telama R (eds) Sport for all. Elsevier Science, Amsterdam, pp 473-483

37. Barnekow-Bergkvist M, Hedberg G, Janlert U, Jansson E (1996) Physical activity pattern in men and women at the ages of 16 and 34 and development of physical activity from adolescence to adulthood. Scand J Med Sci Sports 6:359-370

38. Allender S, Cowburn G, Foster C (2006) Understanding participation in sport and physical activity among children and adults: a review of qualitative studies. Health Educ Res 21:826-835 
39. Lunn PD (2010) The sports and exercise life-course: a survival analysis of recall data from Ireland. Soc Sci Med 70:711-719

40. Rhodes RE, Smith NE (2006) Personality correlates of physical activity: a review and meta-analysis. Review $\mathrm{Br} \mathrm{J}$ Sports Med 40:958-965

41. O'Brien Cousins S, Vertinsky P (1995) Recapturing the physical activity experiences of the old: a study of three women. J Aging Phys Act 3:146-162

42. O'Brien Cousins S (1997) Elderly tomboys? Sources of selfefficacy for physical, activity in late life. J Aging Phys Act 5:229243

43. McPherson BD (1995) Aging and active lifestyles: a cross-cultural analysis of factors influencing the participation of middle-aged and elderly cohorts. In: Harris S, Heikkinen E, Harris WS (eds) Physical activity, aging and sport IV. Center for the Study of Aging, Albany, pp 293-308

44. King AC, Kiernan M, Ahn DK et al (1998) The effects of marital transitions on changes in physical activity: results from a 10-year community study. Ann Behav Med 20:64-69

45. Corder K, Ogilvie D, van Sluijs EMF (2009) Invited commentary: physical activity over the life course-whose behavior changes, when, and why? Am J Epidemiol 170:1078-1081

46. Raymore L, Barber B, Eccles J (2001) Leaving home, attending college, partnership and parenthood: the role of life transition events in leisure pattern stability from adolescence to young adulthood. J Youth Adolesc 30:197-223

47. Allender S, Hutchinson L, Foster C (2008) Life-change events and participation in physical activity: a systematic review. Health Promot Int 23:160-172

48. Pinto BM, Trunzo JJ, Reiss P, Shiu SY (2002) Exercise participation after diagnosis of breast cancer: trends and effects on mood and quality of life. Psycho Oncol 11:389-400

49. Satia J, Campbell M, Galanko J, James A, Carr C, Sandler R (2004) Longitudinal changes in lifestyle behaviours and health status in colon cancer survivors. Cancer Epidemiol Biomark Prev 16:1022-1031

50. Brown WJ, Heesch KC, Miller YD (2009) Life events and changing physical activity patterns in women at different life stages. Ann Behav Med 37:294-305
51. Touvier M, Bertrais S, Charreire H, Vergnaud AC, Hercberg S, Oppert JM (2009) Changes in leisure-time physical activity and sedentary behaviour at retirement: a prospective study in middleaged French subjects. Int J Behav Nutr Phys Act 37:294-305

52. Chung S, Domino ME, Stearns SC, Popkin BM (2009) Retirement and physical activity: analyses by occupation and wealth. Am J Prev Med 36:422-428

53. Hirvensalo M, Rantanen T, Heikkinen E (2000) Mobility difficulties and physical activity as predictors of mortality and loss of independency in community living older population. J Am Geriatr Soc 48:493-498

54. Edwars P, Tsouros A (2006) Promoting physical activity and active living. The role of local governments. World Health Organization (WHO). Available at http://www.euro.who.int

55. Scott F, Young A, Dinan-Young S, Harding M, Lewis S, Fisken S (2008) EUNAAPA Work Package 5. Expert survey on physical activity programmes and physical activity promotion strategies for older people. Available at http://www.eunaapa.org/media/crossnational_report expert_survey_on_pa_programmes_and_promotion_strategies_2008. pdf

56. Laurin D, Verreault R, Lindsay J, MacPherson K, Rockwood K (2001) Physical activity and risk of cognitive impairment and dementia in elderly persons. Arch Neurol 58:498-504

57. McAuley E, Blissmer B, Marquez DX, Jerome GJ, Kramer AF, Katula J (2000) Social relations, physical activity, and well-being in older adults. Prev Med 31:608-617

58. McAuley E, Katula J (1998) Physical activity interventions in the elderly: influence on physical health and psychological function. In: Schulz MPLR, Maddox G (eds) Annual review of gerontology and geriatrics. Springer, New York, pp 115-154

59. American College of Sports Medicine, Chodzko-Zajko WJ, Proctor DN, Fiatarone Singh MA, Minson CT, Nigg CR, Salem GJ, Skinner JS (2009) American College of Sports Medicine position stand. Exercise and physical activity for older adults. Med Sci Sports Exerc 41:1510-1530

60. Dunn AL, Blair SN, Marcus BH, Carpenter RA, Jaret P (2001) Active living everyday. Human Kinetics, Champaign

61. Philippe FL, Vallerand RJ (2008) Actual environments do affect motivation and psychological adjustment: a test of self-determination theory in a natural setting. Motiv Emotion 32:81-89 